\title{
Announcement
}

\section{Ninth International CODATA Conference}

CODATA, the Committee on Data for Science and Technology, is an interdisciplinary committee of ICSU-the International Council of Scientific Unions - and deals with data of importance to science and technology, their compilation, critical evaluation, storage and retrieval. CODATA embraces all fields represented within the member Unions of ICSU, i.e. the physical, earth and life sciences. CODATA aims to promote data compilation and evaluation, to improve the reliability of data presentation, to improve the reliability of data presentation, to upgrade the quality of data collections, to produce a condensation of the literature, to improve data accessibility, and to improve the training and status of data compilers and evaluators.

The Ninth International CODATA Conference, organized by the Israel Committee for CODATA, and under the auspices of the Israel Academy of Sciences and Humanities and the National Council for Research and Development, will be held on 24-27 June 1984 in Jerusalem, Israel.

The scientific program of the Conference is built along two avenues: Sessions and Symposia. Sessions deal with broad interdisciplinary or disciplinary topics, and consist of an invited paper and oral/poster contributed papers. Symposia deal with specific, narrowly defined and well framed numerical data topics within one subdiscipline. Symposia are organized by experts in the various disciplines and will not include contributed papers. In addition, Panel Discussions, on topics in which the use of disciplinary numerical data can be applied to other disciplines, are considered.

The Scientific Program Committee comprises A.S. Kertes, Israel (Chairman); J.E. Dubois, France (Vice-Chairman); D. Abir, Israel; H. Behrens, F.R.G.;E.L. Brady, USA; A. Bylicki, Poland; H. Gutfreund, UK; M. Kotani, Japan; P. Melchior, Belgium; and J.H. Westbrook, USA.

Chairman of the Conference Organizing Committee is A.S. Kertes (The Hebrew University of Jerusalem); E. Hoffmann (National Center of Scientific and Technological Information, Tel-Aviv) is Secretary of this Committee.

The Symposia, and their Organizers, are as follows: 
1. Efforts and progress in evaluating and compiling of phase diagrams ( $\mathrm{H}$. Jehn, Max-Planck Institute, F.R.G.)

2. Foundations of multiphase flow (J. Kestin, Brown University, USA)

3. Numerical data in fluid-phase equilibria (A. Fredenslund, Danish Technical University, Denmark)

4. Thermodynamic data for fluids and fluid mixtures (H. Kehiaian, University of Paris, France)

5. Thermophysical properties of fluids and fluid mixtures (J.V. Sengers, University of Maryland, USA)

6. Critical evaluation of thermochemical data (M.V. Chase, The Dow Chemical Company, USA)

7. Numerical data in process metallurgy (C.B. Alcock, University of Toronto, Canada)

8. Compilation in elementary particle physics (F.D. Gault, University of Durham, UK)

9. Data bases and data structures in physics (F.D. Gault, University of Durham, UK)

10. Numerical data for nuclear energy (M. Zifferero, International Atomic Energy Agency, Austria)

11. Data for future technologies (G.C. Carter, National Academy of Sciences, USA)

12. Numerical data for energy systems (S. Iwata, University of Tokyo, Japan)

13. Solid-seawater equilibrium data (R.M. Pytkowicz, Oregon State University, USA)

14. Actual chemical concentrations in the oceans (R.M. Pytkowicz, Oregon State University, USA)

15. Advanced technology and geographic data (V.B. Robinson, City University of New York, USA)

16. Management and analysis of marine geological data (J.M. Botbol, United States Geological Survey, USA)

17. Management and analysis of numerical data in geochemical exploration

(R.G. Garrett, Geological Survey of Canada, Canada-tentative)

18. Geological resources information system (A.L. Clark, International Institute for Resource Development, Austria - tentative)

19. Geostatistical applications in the mining and petroleum industries (M. David, Geostat Systems International Inc., Canada)

20. Data in food science technology (R. Jowitt, The Polytechnic of Central London, UK)

21. Biotechnological data on monoclonal antibodies (A. Bussard, Institut Pasteur, France)

22. Data needs for genetic engineering/biotechnology $(R, R$. Colwell, University of Maryland, USA)

23. Nucleic acid and protein sequence, analysis and evaluation (J. Sussmann and E. Trifunov, The Weizmann Institute of Science, Israel)

24. X-ray structure, storage and retrieval, and correlation of protein nucleic 
acid structural data (J. Sussmann, The Weizmann Institute of Science, Israel)

25. Stability of proteins and protein complexes in aqueous solutions-tentative (R.L. Biltonen, University of Virginia, USA)

26. Survey of industrial data needs (J.H. Westbrook, General Electric, USA)

27. Data in material science and technology (J.H. Westbrook, General Electric, USA)

Contributed papers for either oral or poster presentation should fall within the following Sessions:

A. Methodology of scientific consolidation and processing of data (data description, presentation, standardization and normalization; compilation, evaluation and correlation of data; critical analysis and recommended data; scientific indexing and coding)

B. Computerized data bases, technology and management (data banks and centers; search and storage; input, monitoring and updating; retrieval and dissemination; communication languages and protocols; large data networks; users, feedback; economics and marketing; legal aspects)

C. Computer techniques in data and systems analysis (computer assisted conceptions and design systems; simulation, estimation and prediction of complex natural systems; mathematical modelling)

D. Numerical information systems in materials science technology and engineering (properties of substances and mixtures; standards and reference materials; phase diagrams; structure theories; atomic and nuclear data; composite materials data; combustion and energy conversion data)

E. Numerical information processing in biosciences (coding; pattern recognition; drug data; genetic engineering; evolutional heritage; human physiological and population data; toxicological information systems; plant breeding)

F. Numerical data processing in geosciences (geoscience field data capture; remotely sensed data in geology, oceanography and meteorology; environmental information systems and automatic cartography; artificial satellites)

A preliminary registration form for the Conference appears on the following page. (Please photocopy if required.) 


\section{Ninth International CODATA Conference}

\section{4-27 June 1984, Jerusalem, Israel}

\section{PRELIMINARY REGISTRATION FORM}

Please type or write in block letters, and air mail to:

The Secretariat, Ninth International CODATA Conference, 122 Hayarkon Street, P.O. Box 3054, 61030 Tel-Aviv, Israel; tel. +9723222217/8/9; telex 341132 CONV IL; cable KOPCON TEL AVIV.

Surname:.

First Name:.

Position/Title:

Institute:

Mailing Address:

The probability that $I$ shall attend the Conference is: definite $\square \quad$ good $\square \quad$ fair $\square$

I shall be accompanied by person $/ \mathrm{s}$

I intend to submit a paper for oral/poster presentation at Session/s (letters).

I plan to attend Session/s (letters).

I plan to attend Symposia (numbers).

Signature.

Date. ........... 